\title{
32. The Accessory Optic Tract in the Rat
}

\section{Evidence for the Retino-Suprachiasmatic Tract*)}

\author{
By D. Takao RYU \\ Department of Anatomy, Hyogo College of Medicine, Nishinomiya 663 \\ (Communicated by Teizo OGAWA, M. J. A., March 12, 1979)
}

The suprachiasmatic nucleus (sch), a pair of small oval nuclear groups, is located in front to a little before the beginning of the hypothalamic arcuate nucleus. Its function is reported as probably having some affection regarding certain neuroendocrine metabolism in some animals, e.g., the ovulation cycle in the rat by Critchlow (1963), Singh and Greenwald (1967), and Butler and Donovan (1971), pineal induced alteration of the estrous cycle in the hamster by Sorrentono, Jr. and Reiter (1970), and the loss of a circadian rhythm in the rat by Moore (1972), and Ibuka and Kawamura (1975), etc. In contrast, the suprachiasmatic nucleus receiving a direct fiber projection coming from optic nerve (on) was observed and demonstrated in the light and electron microscopic studies( ${ }^{4), 5), 7), 8), 10), 12)-14,18), 19)}$ some time ago. Also a retino-suprachiasmatic connection was previously recognized in relation to the accessory optic system (aof) in a report ${ }^{15)}$ studied using the anterograde degeneration method.

This study attempts to describe a pattern of the direct fiber pathway of the retino-suprachiasmatic connection in the rat. Four albino rats (Wistar, both sexes, 250-300 gm, housed under dark/light: 10h/ $14 \mathrm{~h}$ condition) selected from a group of the retinofugal experimental animals which had been used in the following experiments. Under ether anaesthesia, the animals had one eye enucleated unilaterally with an aseptic small knife. Four or five days after the operations, each animal was sacrificed and perfused through the heart with $10 \%$ formol-saline. Then the brain was removed and stored in the same fixative for one week. After that, the brain was frozen and sectioned serially in the coronal ( 3 cases) and the horizontal ( 1 case) planes respectively, each section at a thickness at $25 \mu \mathrm{m}$. These sections were prepared by means of the Fink-Heimer (1967) and Nauta-Gygax (1954) techniques.

The following account was based primarily on the serial coronal sections. A small number of aberrant degenerating fibers ascending

*) This work was carried out when the author was working in Juntendo University School of Medicine. 


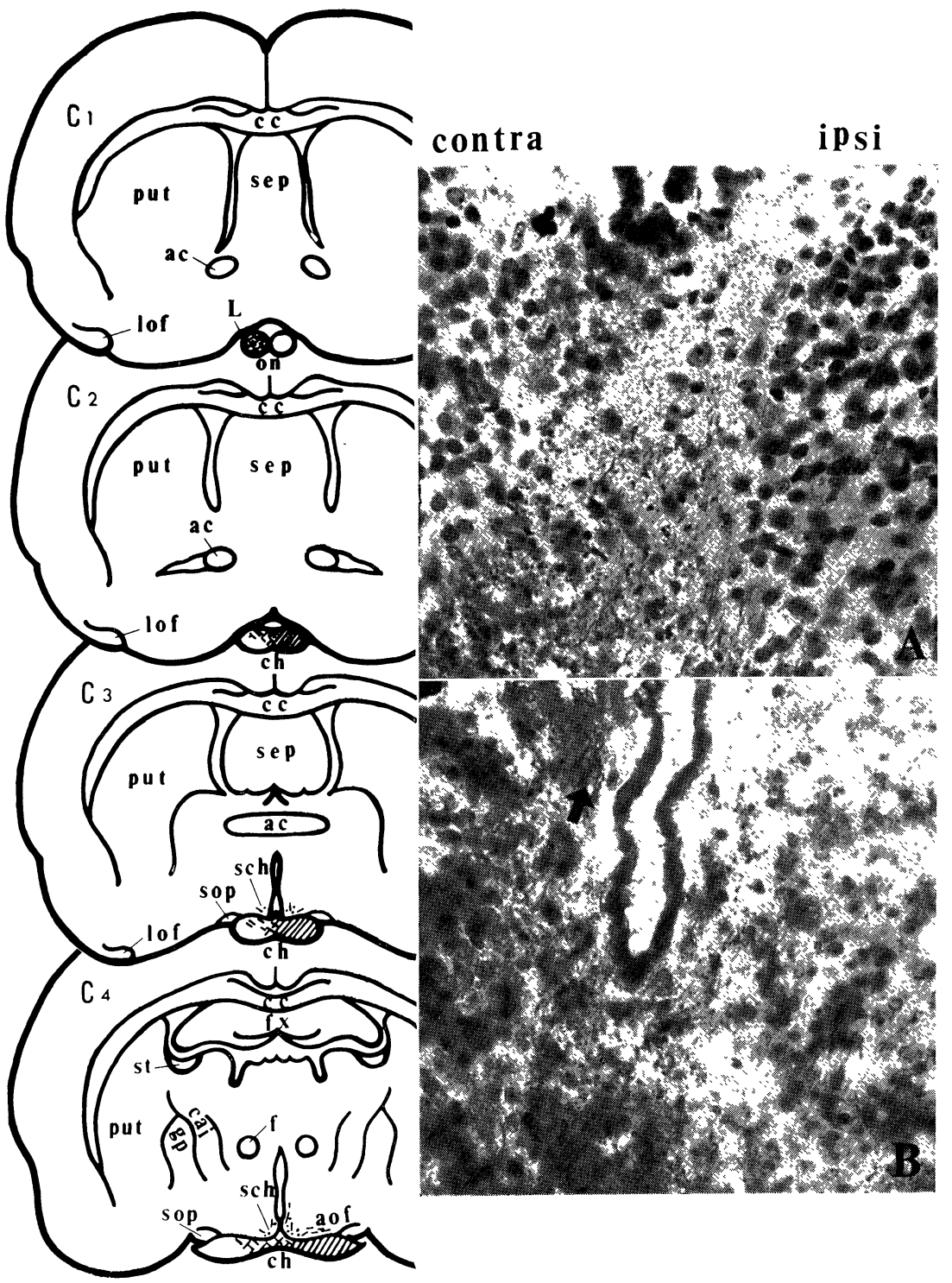

Fig. 1.

Fig. 2.

Abbreviations: ac, anterior commissure; cai, internal capsule; cc, corpus callosum; f, fx, fornix; gp, globus pallidus; lof, lateral olfactory tract; put, putamen; sep, septum; sop, supraoptic nucleus; st, stria terminalis.

Fig. 1. A serial coronal diagram illustrating the retino-suprachiasmatic pathway and terminal area. $C_{1}$ is the rostralmost section. $C_{4}$ is the caudal section. The lesion $(\mathrm{L})$ is on the left side. The hatch area indicates the primary optic tract. The small dash points to the projection fiber. The stippling indicates the terminal area.

Fig. 2. A: The photomicrograph shows the optic termination in the ventromedial area of the suprachiasmatic nucleus. The coronal section, $\times 200$, Fink-Heimer. B: The photomicrograph shows the degenerating fibers (arrow) passing caudally into the third ventricular border. The coronal section, $\times 200$, Fink-Heimer. 
from the supraoptic crest posteriorly at the median portion of the optic chiasm (ch) were found; these fibers were decussated and emanated bilaterally into the ventral and medial sides of both suprachiasmatic nuclei. Then these fiber terminals were ended in the ventromedial area of the suprachiasmatic nucleus. The terminal endings (see Fig. 2) were shown more clearly on the contralateral (contra) side than on the ipsilateral (ipsi) side of the enucleation. However, near the medial side of the suprachiasmatic nucleus, few degenerating fibers appeared penetrating caudally into the inferior border of the third ventricle. These degenerating fibers did not spread to any termination on the ventricular border or into the preoptic-ventromedial nucleus. The findings suggested that the direct fiber tract occurred apparently arising from the optic nerve into the suprachiasmatic nucleus. Evidence for the retino-suprachiasmatic tract may be proposed to help in the understanding of the optic-hypothalamic-hypophyseal system concerning the neuroendocrine metabolism. In addition, efferent connections of the suprachiasmatic nucleus remain to be resolved in further investigation.

Summary. A direct fiber connection of the retino-suprachiasmatic pathway was examined by the Fink-Heimer and Nauta-Gygax techniques. It was obtained that the retino-suprachiasmatic fibers were distributed bilaterally into the suprachiasmatic nucleus in the rat. The significance of the optic-hypothalamic connection is concerned.

\section{References}

1) Butler, J. E. M., and Donovan, B. T.: J. Endocrin., 49, 293 (1971).

2) Critchlow, V.: Advances in Neuroendocrinology (ed. A. Nalvandov), Univ. of Illinois Press, Urbana, p. 377 (1963).

3) Fink, R. P., and Heimer, L.: Brain Res., 4, 369 (1967).

4) Frey, E.: Acta anat., 4, 123 (1947).

5) Gülder, F. H.: Cell Tiss. Res., 194, 17 (1978).

6) Ibuka, N., and Kawamura, H.: Brain Res., 96, 76 (1975).

7) Knoche, H.: Z. Zellforsch., 51, 658 (1960).

8) Mai, J. K., and Junger, E.: Cell Tiss. Res., 183, 221 (1977).

9) Moore, R. Y., and Eichler, V. B.: Brain Res., 42, 201 (1972).

10) Moore, R. Y., and Lenn, N. J.: J. Comp. Neur., 146, 1 (1972).

11) Nauta, W. J. H., and Gygax, P. A.: Stain Tech., 29, 91 (1954).

12) Nauta, W. J. H., and Haymaker, W.: The Hypothalamus (eds. W. Haymaker, E. Anderson, and W. J. H. Nauta), Charles C. Thomas, Spring field, Illinois, p. 187 (1969).

13) Printz, R. H., and Hall, J. L.: Anat. Rec., 179, 57 (1974).

14) Rieke, W. O.: Anat. Rec., 130, 363 (1958).

15) Ryu, D. T.: Proc. Japan Acad., 55B, 157 (1979).

16) Singh, K. B., and Greenwald, G. S.: J. Endocrin., 38, 389 (1967). 
17) Sorrentino, Jr., S., and Reiter, R. J.: Gen. Comp. Endocrin., 15, 39 (1970).

18) Sousa-Pinto, A.: Exp. Brain Res., 11, 528 (1970).

19) Sousa-Pinto, A., and Castro-Correia, J.: Exp. Brain Res., 11, 515 (1970). 